\title{
Learner-Centered (LCI) Vs. Teacher-Centered (TCI) Instruction: A Classroom Management Perspective
}

Mary Kennedy Minter, Education Consultant, USA

\begin{abstract}
Teacher education should incorporate management and leadership training with an emphasis on student audience analysis. Macro perspectives of teaching are needed for a workable approach to the management of education.
\end{abstract}

\section{INTRODUCTION}

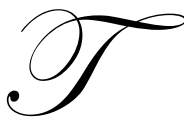

he process and skills needed for effective teaching should not be dichotomized to just learner vs. teacher-centered paradigms (LCI vs. TCI). For life-long learning by students and teachers, many variables need to be considered. The major issues and concepts to be discussed are:

- Definitions related to LCI and TCI,

- References to higher education historical factors,

- $\quad$ The teacher as a manager and leader.

The main contention of this paper is that classroom teachers are both managers and leaders. Therefore, management concepts should apply to the classroom environment. From my 50 years of experience in education, the business management models have not been effectively utilized in teacher/professor education.

This author proposes that teacher education or "pedagogy" (learning how to teach) should incorporate management and leadership concepts with an emphasis on student audience analysis.

\section{Basic Definitions Of LCI And TCI (Related To Pedagogical Concepts)}

Perhaps the most efficient way to describe a dichotomized view of LCI vs. TCI is through a listing of their respective characteristics:

\begin{tabular}{|l|l|}
\hline \multicolumn{1}{|c|}{ Learner-Centered Instruction } & \multicolumn{1}{c|}{ Teacher-Centered Instruction } \\
\hline Focus is on both students and instructor & Focus is on instructor \\
\hline $\begin{array}{l}\text { Instructor models; students interact with instructor and } \\
\text { other students }\end{array}$ & Instructor talks; students listen \\
\hline $\begin{array}{l}\text { Students answer each other's questions using instructor as an } \\
\text { information source }\end{array}$ & Instructor answers students' questions \\
\hline Students have some choice of topics & Instructor chooses topics \\
\hline $\begin{array}{l}\text { Students evaluate their own learning along with instructor's } \\
\text { evaluations }\end{array}$ & Instructor only evaluates student learning \\
\hline Classroom is often noisy and busy & Classroom is basically quiet and controlled* \\
\hline
\end{tabular}

*Listing adapted from Mayflor Markusi, "Instruction Paradigms: Learner-Centered versus Teacher-Centered;" Special

Educational Newsletter, ed./published by S. Forsyth, Jan. 2, 2009.

(http://www,.brighthub.com/education/special/articles/5485.aspx\#ixzz16tZqJ3OW) 
LCI and TCI, as pedagogical concepts, necessitate a reminder of the meanings related to "pedagogy." The dictionary provides an interesting paradox with the definitions of pedagogy (n) and pedagogue (n):

Pedagogy refers to the "process" of teaching; also, "the art, science, or profession of teaching."

Pedagogue, in contrast, refers to the French derivative meaning "to lead," especially, a "dull, formal, or pedantic teacher." Unfortunately, the latter definition is one that continues to abound in our secondary and higher education environment with passive learners getting lost in the process.

\section{SIGNIFICANT HISTORICAL PERSPECTIVE RELATED TO LCI AND TCI}

\section{Reflections on John Dewey concepts from 1897-1930's:}

This author's viewpoint is that many of our current education concepts are based on historical paradigms; the modern interpretations just exemplify old ideas with new labels.

For example, John Dewey, as early as 1902 discussed educational pedagogy in his book, The Child and the Curriculum. The issue Dewey describes in his early writing is that there is a conflict between just focusing on the subject matter and thus producing an inactivity of the student. (Dewey, 1902, p.13) The point is that content needs to be presented in such a way that the student can relate the information to previous experiences and knowledge and in so doing, the student builds relationship, synthesis, and a deeper learning experience. However, Dewey was not proposing a complete "learner-centered" approach at the detriment of reducing the importance of the subject matter. He was proposing a balance rather than a LCT/TCT dichotomy, i.e., we need both approaches in order to be effective in our instructing. "According to Dewey, the teacher should not be one to stand at the front of the room doling out bits of information to be absorbed by passive students. Instead, the teacher's role should be that of facilitator and guide. ... thus the teacher becomes a partner in the learning process, ...." (reference to Dewey, 1897, "My Pedagogic Creed"); http://en.wikipedia.org/wiki/John_Dewey, "On education."

For over one hundred years since Dewey's view of pedagogy, our nation's education has seemed to resist the Dewey approach and has maintained its reliance on the one-way model of communication within the classroom where "pedagogue" behavior persists. Yes, we have the technological intervention of the infamous "Power Point" which serves as an outline for the "pedagogue" to follow while staring at the screen rather than interacting and relating to the students in a darkened classroom. We also have the intervention of "on-line" learning which further puts the learner in a passive and isolated role. The basic issue appears to be that teachers are losing the "art of improvisation," i.e., the art of managing and leading group dynamics that can produce the synergy needed for learner-centered instruction. (newsroom@insidehighered.com "Lost Art of Teaching, June 2010)

Ironically, this author/teacher was taught Dewey's education philosophy and balanced approach to teaching while obtaining teacher education and certification in 1956-1960. However, in addition to the use of the "Dewey approach" in a 50-year teaching career, the experience produced a need to use leadership and management concepts which this author believes is an inherent part of any educational approach and will be discussed in the following section.

\section{The Teacher As A Manager And Leader}

It seems frugal to dispose of definitions first. Although many academicians are proponents of separating "manager" and "leader" concepts/skills, this author supports the Whetton and Cameron view that: "Traditionally, leadership is used to describe what individuals do under condition of change. . .Management, on the other hand, has traditionally been used to describe what executives do under conditions of stability." However, "Managers cannot be successful without being good leaders, and leaders cannot be successful without being good managers." (Whetton \& Cameron, 1998, p.14) That certainly seems to be the case with classroom dynamics producing the need for management and leadership skills. 
Although teachers/professors may not perceive their role to be that of a manager/leader in classroom instruction, they do, in fact, perform these roles. For example, in an interview study of 402 highly effective business managers, the following behavioral characteristics were identified as the top 10 each of these characteristics can be directly related to a professor's role as a manager (Minter, 2009, p.57).

1. Verbal communications (including listening)

2. Managing time and stress

3. Managing individual decisions

4. Recognizing, defining, and solving problems.

5. Motivating and influencing others

6. $\quad$ Delegating

7. Setting goals and articulating a vision

8. Self-awareness

9. Team building

10. Managing conflict (Whetton \& Cameron, 1998, p.7)

\section{Transactional vs. Transformational Leadership:}

Related to the teacher's leadership role, history indicates that the preference has been for "transactional leadership." This style of leadership makes the following assumptions: (1) that students will be motivated by "reward and punishment" and (2) that students are "subordinates" to the teacher, therefore, students are expected to do what their leader/manager tells them to do. These assumptions certainly do not reflect the spirit of learnercentered teaching; however, it is indicative of the traditional teacher-centered, pedagogue model.

In contrast, the learner-centered concept requires a transformational leadership concept and skills, i.e. 1) the leader acts as a mentor, who models sharing behavior by establishing trust, empathy, and two-way communications and 2) encouraging and motivating creative thought among the students. "Charisma" is a term often associated with this concept. (James M. Burns, 1978; B.M. Burns, 1994, 1998)

\section{Historical Leadership/Management Models Are Applicable To Classroom Teacher's Role:}

There are many, well-known models in the business management and behavioral literature that can be applied to the classroom dynamics and leadership skills needed by teachers. This author contends that it is a very unfortunate, academic void that teacher education has neglected to encompass historical concepts and models from business leadership/management and the social psychology literature. Examples of these seminal research contributions are briefly discussed below. All of these classic concepts can easily be related to the current literature on Learned-centered and Teacher-centered instruction (LCI and TCI).

For example, as early as the 1930's seminal research was being done at the University of Michigan by such social psychologists as: Kurt Lewin, Ronald Lippitt, Ralph K. White, and Rensis Likert (1930-1940). From this large body of research and publications came such famous concepts as: the "Likert scale" for social survey measurements and the management system literature related to autocratic, consultative, and participate styles of leadership.

Classic leadership concepts have been graphically described by the such authors as Tannenbaum \& Schmidt's Leadership Continuum (1958), Hersey and Blanchard's Situational Leader model (1970's); Blake \& Mouton's Managerial Grid (1964).

Tannenbaum \& Schmidt's Management delegation continuum (1958) graphically illustrates various level of authority vs. freedom used by managers with subordinates, i.e., from authoritative to participatory. The continuum spans the options of the manager (teacher) making and announcing the decision (e.g., the course syllabus), through "selling" that approach to allowing questions and feedback and finally, more freedom by allowing students to develop options for the course and decide on actions. Obviously this approach relates to a Learnercentered/Teacher-Centered Instruction continuum. It also is related to the 1930's initial model of manager style of 
autocratic to democratic (Lewin, Lippitt, Likert, et.al.), to Hersey and Blanchard's situational leadership model, and to Blake and Mouton's managerial grid.

During the 1970's Paul Hersey (Situational Leader) and Ken Blanchard (One Minute Manager) came together to produce the first edition of Management of Organizational Behavior (now in its $9^{\text {th }}$ edition). The results of these writings produced the often adapted concept model of "situational leadership." As their diagram indicates, there is a definite emphasis on analysis of the followers (students) which develops the following scenarios:

- If the followers' development/commitment level is low, the supportive leadership style may have to be more autocratic, i.e. "telling" followers what to do.

- If the followers' development/commitment is at a medium level, then perhaps a "selling style" of leadership can be used.

- If the followers' development/commitment level is at a higher level, then a more "participating" style of leadership can be used.

- If the followers' development/commitment level is at a very high level, then a more complete "delegating" style of leadership can be used.

This leadership model is very adaptable to the teacher's role as leader. The teacher must determine the developmental and commitment level of the students regarding the subject matter, student experience, and maturity. Ironically, ALL THREE STYLES come into play within average classroom experiences. For example, NEW subject matter may involve a "telling style," whereas, there may need to be a definite "selling style" used in order to "sell" the students on the importance of the subject matter to be learned. Both of these communication needs can be enhanced by using the "participating and delegating" styles of leadership. For example, students can be asked to participate in discovering "why" the subject matter is important, thus helping with the "selling" need. The teacher can "delegate" information gathering to the students and then have them "teach" the class in a particular aspect of the topic, thereby, utilizing a common axiom that "we really learn what we teach others."

Blake Mouton's Managerial Grid (1964)) is also applicable to the classroom teacher and learning process. The model diagrams two axis's: one a concern for production; for example, how much and how well have students learned - the typical assessment tools for student achievement; second, a concern for people, for example the teacher's viewpoint in regards to the students in the class-is there a low concern for students or high concern for their welfare? Is there an emphasis on "outcomes" through national assessment tests? One concern that this author has when comparing our USA students' scores with other countries, e.g. China and Japan, is that it does not seem to be an even playing field (just like our monetary system comparisons). For example, far eastern countries education system puts a strong emphasis on production/output, i.e., student test scores through memorization and definitely a "telling leadership style" (per Hersey and Blanchard). In contrast, the USA culture emphasizes the concern for people/students as exemplified by our "cafeteria approach to curriculum" where students have more opportunities for variety in selecting courses in which they are interested, i.e. selecting college preparatory courses or more general, trade-related courses. The most significant difference in far eastern higher education is that USA students have a choice of community colleges which have minimum or no grade point average entry requirements.

Four-year colleges also have many different approaches and entry level requirements. In general, we have a wide diversity of educational standards in higher education that allow our many levels of students to succeed, IF they have the motivation and persistence to do so.

An interesting study that could be done is to compare/contrast the difference in scores by USA students versus those from far eastern or other global countries based on comparable college entry requirement statistics and then compare the graduation results of that stratified sample. In contrast to a broad statistical comparison, the results with the defining and comparable criteria might find the USA students equal to or surpassing the Asian students in productivity and results.

\section{Open Systems Model: A Gestalt View Of The Learner/Teacher Process}

In reference to John Dewey and thinking beyond classroom pedagogy, one needs to remember that Dewey, as a professional philosopher, viewed public education as being a foundation for our democratic social process, i.e., 
an educated population is necessary for a democratic form of government to survive (by and for the people). For example, "education is a regulation of the process of coming to share in the social consciousness and that the adjustment of individual activity on the basis of this social consciousness is the only sure method of social reconstruction." (Dewey, 1897, p.16)

This gestalt view of public/college education points to the imperative need to analyze not only the micro view of education (the classroom learning environment), but also the macro view (the organizational structure of education from an open system, managerial viewpoint).

The use of the open system concept to analyze the student/teacher learning process can help to visualize the complexity of the learning organizations' system. The key components of the open system model are: "input, resource conversion (process), output, permeable boundaries, and feedback." This concept forces us to consider the many variables that affect the dynamic and interdependent teaching/learning process.

\section{Input Components For Classroom Process:}

"Inputs" include, but are not limited to: students and teachers (their backgrounds encompassing culture, health, education experiences, skills, attitudes/behaviors, and interpersonal relationships coming into the classroom learning environment. The key components of input are: (1) the teacher's expertise and skills in subject matter, instructional management/methods, and communication within the classroom setting, (2) the student's readiness to learn (basic skills, such as: reading, writing, math) and attitude/behavior/heath factors, and (3) the student's "baggage" that one brings into the classroom (e.g., home and parental issues, peer pressure, poverty, environment, etc.).

\section{"Permeable Boundaries" Related To Input:}

The environment of the college/university and classroom is part of the "permeable boundaries." That is, how do the relevant environmental factors affect the learning/conversion process? The following are just a few examples of permeable boundary factors affecting both students and teachers: the "state of the country (e.g., economy, war, threats) including the "state of the immediate community environment (e.g., economy, threats of violence, school facilities, cultures) and family environment (economy, support, physical/mental status, genetics and family cultures, educational support). As one can perceive, these permeable boundary factors are often beyond the control of the schools, i.e., teachers, administrators, and communities.

\section{Resource Conversion Component For Classroom Process:}

Within the "formal organizational structure" of the classroom, the important process of "resource conversion" takes place. This is a crucial stage of the organizational process which can be interpreted as the "conversion of information dissemination and management" between teachers and students, i.e., information transplanting, managing, storage, and synthesizing factors. However, as stated above, the conversion stage is greatly affected by permeable boundaries (environmental factors), including input factors of the teachers and students.

\section{Output Components Of Classroom Process:}

Critical parts of the open system concept, as it relates to education, are the "outputs and feedback." A key "output" is proof that students have learned, at various levels of learning, the subject matter and skills transmitted during the conversion stage. One important "feedback" is the kind of assessments used that help to prove learning has actually takes place or that skills have been acquired and can be executed effectively. "Feedback" is needed through the results of testing, practice, and other evaluation methods to improve the student's education process and results. (Minter, 2010. p.35)

\section{General View Of The Open System And The Classroom Process:}

From this open system view, this author's opinion has always been that the teacher should not be considered the only ones responsible for students' learning. This author has concluded that the following statement 
is a gross over generalization: "If a student has not learned, a teacher has not taught." In contrast, it is a 50-50 proposition - students must be prepared and open to learning which includes family/home, community environmental and contributing factors; teachers must be competent in their subject area AND competent in classroom management, communication, and technology. Therefore, the current proposition that teacher's pay should be based on students' grades is NOT a valid measurement. This requirement would invariably lead to "grade inflation" (which is currently a dangerous issue) and a disservice to students' who need to learn "how to learn" and to acquire synthesized and meaningful knowledge and skills. The point is: please don't put the "burden of proof" on the teacher for student's learning ability, performance, and academic accomplishment. The teacher is just ONE of many variables involved in the student's performance. Genetics, home and community environments are major factors affecting student learning. For example, poor, inner city school students from one parent home environment and crime ridden communities have a much more difficult time succeeding than the student from a high economic, suburban school with continuing parent and community support. In addition, school buildings and other support systems differ greatly in this country.

The environmental factors effecting high school education also is a significant variable for those who attempt higher education; for example, if the student comes into a college environment from an unsuccessful high school experience and is not prepared for the higher education level, then she/he is at a great disadvantage. Students who go through a two-year college experience may have an advantage; however, they also may be not be prepared for advanced college-level work.

The emphasis on higher education (BA) in the USA may be an unrealistic assumption, i.e., due to the economic environment (2010) and fewer jobs for high school and/or trade school students, young people may be perceiving higher education as a way to "wait out" the recession syndrome and to help them get a better paying job in the future. However, even attempts to continue with post secondary education has proven unattainable for many; e.g. the national average for college dropouts during the freshman year is in the 50-60 percent range.

\section{Why Are These Historical, Management, And Leadership References Relevant To Learner vs. Teacher- Centered Instruction In The Classroom?}

Placed in the role of managers, leaders, and instructors, teachers should be aware of the many variables affecting the learning process (e.g., the open-system viewpoint) and the many manager/leadership skills, styles, and processes that can assist in improving the classroom instruction and enhancing students' learning. At the very least, the open system model should support the need for an improved practicum for teacher education. Why? Because the open system concept illustrates the complexity of the communication, management, learning processes involved in classroom instruction which directly affect the results (outputs), that is, assessment of learning (AOL). The caveats, of course, are: (1) IF the input material (teacher and student) is not of high quality, (2) IF the process (resource conversion) is not competently facilitated, (3) IF the permeable boundary factors are uncontrollable or insurmountable, and (4) IF the teacher is more concerned about student performance and less concerned about teacher-student relationships and mentoring, THEN the outputs (results) of the teaching/learning process may not meet quality standards. (Minter, Jan. 2009, p. 30)

As mentioned previously, in the learner vs. teacher-centered instruction, there must be a balanced approach to management/leadership within the classroom. All of the concepts discussed above necessitate student (audience/follower) self-assessments and analysis in order to improve the classroom environment and output.

It is recommended that several self-assessment inventories be given at the beginning of any course. These can be completed and scored outside of class and students can voluntarily share and discuss results in class. Three examples that the author has used for many years are: (1) the Kolb's Learning Style Inventory, (2) a listening inventory, and (2) a cognitive style inventory. (Minter, Jan. 2009, p. 32)

\section{CONCLUSION}

Teacher education or "pedagogy" (learning how to teach) should incorporate management and leadership concepts with an emphasis on student audience analysis. Over 100 years of research and concept development in the 
disciplines of philosophy, social psychology, education, and business management have led to a vast body of tools to use in the area of education, e.g., from Dewey, Lewin, Lippitt, Maslow, McKeachie, et.al. In this author's opinion, it is a sad commentary that we continue to concentrate on general concepts such as Learnercentered/Teacher-centered instruction and critical thinking. We need to search and respond to the myriad of macro and micro perspectives in other disciplines in order to gain a more workable approach to the management of education.

The responsibility for improving learning at the higher education level (as well as other levels), needs to be BALANCED among support and competency of: parents, administration, teachers, researchers, AND students. Learning is not a spectator sport. (Chickering, 1981). Students must be convinced that learning is important for them and then become self-motivated to obtain the skills needed for "learning how to learn." The process is one of "life-long learning." Students must accept this axiom before self-motivated, learner-centered instruction will be successful.

\section{AUTHOR INFORMATION}

Mary Kennedy Minter, Ed.D., has been a college teacher for over 30 years and specializes in faculty development consulting. She has taught instructional communication and business management at Texas Christian University, U. of Texas, Arlington, Texas Wesleyan University, University of Akron, and Cleveland State University. Her degrees are: doctorate in Higher Education Administration, U. of Michigan; Master's degree in Organizational Communication/Industrial Relations from Purdue University; and Bachelor of Arts from Ohio University.

\section{REFERENCES}

1. Bass, B. M. (1998). Transformational leadership: Industrial, military, and Educational impact. Mahwah, NJ: Erlbaum.

2. Bass, B. M. (1994). Improving organizational effectiveness through transformational Leadership. Thousand Oaks, CA: Sage Publications.

3. Bass, B. M. (1990) "From transactional to transformational leadership: Learning to share the vision." Organizational Dynamics, (Winter): 19-31.

4. $\quad$ Bass, B.M. (1985). Leadership and performance beyond expectation. New York: Free Press.

5. Bertalanffy, L. von (1968). General system theory: Foundation, development, applications. New York: George

6. $\quad$ Blake, R. and Mouton, J. (1964). The Managerial Grid: The Key to Leadership Excellence. Houston: Gulf Publishing Co.

7. Burns, J. M. (1978). Leadership. New York. Harper \& Row.

8. Chickering, A. W. and Associates. (1981). The Modern American College. San Francisco: Jossey-Bass.

9. $\quad$ Dewey, John. "My Pedagogic Creed,” School Journal. Vol. 54 (1897), pp.77-80.

10. Dewey, John. The Child and the Curriculum. (1902). Chicago, IL: U. of Chicago Press.

11. Hersey, P., \& Blanchard, K. H. (1977). Management of organizational behavior: Utilizing human resources $\left(3^{\text {rd }}\right.$ ed.). Englewood Cliffs, NJ: Prentice Hall.

12. Hunsacker, P.L. \& Cook, C.W. (1986). Managing organizational behavior. Reading, MA: Addison-Wesley Publishing Company.

13. Kobe, David A. (1985) Learning-Style Inventory, Boston, MA: McBer and Company.

14. Lewin, Kurt (1943; 1997). Resolving Social Conflicts \& Field Theory in Social Science. Washington, D.C.: American Psychological Association.

15. Lewin, Kurt; Lippitt, Ronald; White, Ralph K. (1939). "Patterns of aggressive behavior in experimentally created social climates." The Journal of Social Psychology.

16. Lippitt, Ronald. (1940). "An experimental study of the effect of democratic and authoritarian group atmospheres," University of Iowa studies in child welfare.

17. Maslow, A. H. (1962). Toward a psychology of being. Princeton, N.J.: D. Van Nostrand Company.

18. McGregor, Douglas. (1960). The Human Side of Enterprise. New York, NY: McGraw-Hill.

19. McKeachie, Wilbert J. (1999). McKeachie's Teaching Tips: Strategies, Research, And Theory for College and University Teachers. Boston: Houghton Mifflin. 
20. Minter, M.K. (Aug. 2010). "Critical Thinking Concept Reconstructed," Contemporary Issues in Education Research (Vol. 3, No. 8).

21. Minter, M.K. (Dec. 2009). “Actors in Academia-Roles Professors Play,” Journal of College Teaching \& Learning, (Vol., No. 1)

22. Minter, M. K. (Jan./Feb. 2009). "Teaching Inside the Box,” The College Teaching Methods \& Styles Journal (Vol. 6, No.1).

23. Minter, M. K. (Jan. 2008). "Recommendations for Faculty Development," The College Teaching Methods \& Styles Journal (Vol. 4, No. 1).

24. Mitchell, T. R. \& Larson, J. R. (1987). People in organizations: An introduction to organizational behavior. ( $3^{\text {rd }}$ ed.). New York: McGraw-Hill.

25. Tannenbaum, R., \& Schmidt, W. (1958). "How to choose a leadership pattern. Harvard Business Review, 36 (2).

26. Tannenbaum, R., Weschler, I. R., \& Massarik, F. (1987). Leadership and organization: A behavioral approach. New York: Garland Publishing, Inc.

27. Watson, Kittie W. \& Barker, Larry L. (1995). Listening Inventory. San Francisco, CA: Jossey/Bass.

28. Whetten, David A. \& Cameron, Kim S. (1998) Developing Management Skills. Reading, Mass.: AddisonWesley. 